Click

\title{
Measurements of natural uranium concentration and isotopic composition with permil-level precision by inductively coupled plasma-quadrupole mass spectrometry
}

\section{Chuan-Chou Shen}

Department of Geosciences, National Taiwan University, No. 1, Sec. 4, Roosevelt Road, Taipei, Taiwan 106

(river@ntu.edu.tw)

\section{Huei-Ting Lin}

Department of Earth Sciences, National Taiwan Normal University, No. 88, Sec. 4, Tingjou Road, Taipei, Taiwan 116

\section{Mei-Fei Chu}

Department of Geosciences, National Taiwan University, No. 1, Sec. 4, Roosevelt Road, Taipei, Taiwan 106

\section{Ein-Fen Yu}

Department of Earth Sciences, National Taiwan Normal University, No. 88, Sec. 4, Tingjou Road, Taipei, Taiwan 116

\section{Xianfeng Wang}

Department of Geology and Geophysics, University of Minnesota, 310 Pillsbury Drive SE, Minneapolis, Minnesota 55455, USA

\section{Jeffrey A. Dorale}

Department of Geoscience, University of Iowa, 121 Trowbridge Hall, Iowa City, Iowa 52242, USA

[1] A new analytical technique using inductively coupled plasma-quadrupole mass spectrometry (ICPQMS) has been developed that produces permil-level precision in the measurement of uranium concentration $([\mathrm{U}])$ and isotopic composition $\left(\delta^{234} \mathrm{U}\right)$ in natural materials. A ${ }^{233} \mathrm{U}-{ }^{236} \mathrm{U}$ double spike method was used to correct for mass fractionation during analysis. To correct for ratio drifting, samples were bracketed by uranium standard measurements. A sensitivity of $6-7 \times 10^{8} \mathrm{cps} / \mathrm{ppm}$ was generated with a sample solution uptake rate of $30 \mu \mathrm{L} / \mathrm{min}$. With a measurement time of 15-20 min, standards of 30 -ng uranium produced a within-run precision better than 3\% ( \pm 2 R.S.D.) for $\delta^{234} U$ and better than $2 \%$ for $[\mathrm{U}]$. Replicate measurements made on standards show that a between-run reproducibility of $3.5 \%$ for $\delta^{234} \mathrm{U}$ and $2 \%$ for $[\mathrm{U}]$ can be achieved. ICP-QMS data of $\delta^{234} \mathrm{U}$ and [U] in seawater, coral, and speleothem materials are consistent with the data measured by other ICP-MS and TIMS techniques. Advantages of the ICP-QMS method include low cost, easy maintenance, simple instrumental operation, and few sample preparation steps. Sample size requirements are small, such as 10-14 $\mathrm{mg}$ of coral material. The results demonstrate that this technique can be applied to natural samples with various matrices. 
Components: 5912 words, 5 figures, 2 tables.

Keywords: natural uranium; $\delta^{234} \mathrm{U}$; ICP-QMS; permil-level precision.

Index Terms: 1040 Geochemistry: Radiogenic isotope geochemistry; 1094 Geochemistry: Instruments and techniques; 1115 Geochronology: Radioisotope geochronology.

Received 12 March 2006; Revised 21 June 2006; Accepted 10 July 2006; Published 20 September 2006.

Shen, C.-C., H.-T. Lin, M.-F. Chu, E.-F. Yu, X. Wang, and J. A. Dorale (2006), Measurements of natural uranium concentration and isotopic composition with permil-level precision by inductively coupled plasma-quadrupole mass spectrometry, Geochem. Geophys. Geosyst., 7, Q09005, doi:10.1029/2006GC001303.

\section{Introduction}

[2] The elemental and isotopic abundances of uranium have been extensively used to explore biogeochemical and physical processes in diverse fields of the Earth sciences [e.g., Bourdon et al., 2003]. Low uranium concentrations ([U]) and low abundances of ${ }^{234} \mathrm{U}$ in most natural samples, however, constrain many applications due to measurement limitations. Alpha spectrometry methods have been used to quantify uranium radionuclides for five decades [Barnes et al., 1956; Ivanovich and Harmon, 1992], but large sample size requirements and the advent of techniques with vastly improved throughput and analytical precision have pushed alpha-counting techniques toward obsolescence. Thermal ionization mass spectrometry (TIMS) advanced analytical capabilities with permil-level precision in the 1980s [e.g., Chen and Wasserburg, 1981; Edwards et al., 1987; Rubin et al., 2005]. Subsequently, various inductively coupled plasma mass spectrometry (ICP-MS) methods have been improved yielding permil-to-sub-permil precision measurements [Shaw and Francois, 1991; Halliday et al., 1995; Stirling et al., 1995, 2000; Luo et al., 1997; Becker et al., 1999; Hinrichs and Schnetger, 1999; Becker and Dietze, 2000; Pietruszka et al., 2002; Shen et al., 2002; Deschamps et al., 2003; Robinson et al., 2004; Andersen et al., 2004; Fietzke et al., 2005]. Merits of ICP-MS techniques include short measurement times, few sample preparation steps, high sample throughput, high ionization efficiency, and massdependent discrimination.

[3] With flat-topped peaks, ICP-sector field (SF)MS and multicollector (MC)-ICP-MS yield highprecision isotopic analyses [Luo et al., 1997; Stirling et al., 2000; Turner et al., 2001; Pietruszka et al., 2002; Shen et al., 2002; Deschamps et al., 2003; Robinson et al., 2004; Andersen et al., 2004;
Fietzke et al., 2005]. Luo et al. [1997] were the first to develop techniques with a MC-ICP-MS, a Fisons Plasma 54, which yielded 1.2-1.4\%o analytical precision using 300-400 ng of uranium. Secondary ion mass spectrometry (SIMS) and laser-ablation MC-ICP-MS have been used for the in situ analysis of $U$ isotopes in U-rich carbonates [Stirling et al., 2000], zircons [Reid et al., 1997], basalts [Bourdon et al., 1996], and igneous minerals [Bourdon et al., 1994]. These techniques have been reviewed by Halliday et al. [1998] and Goldstein and Stirling [2003]. Samples with uranium levels of 5-40 ng can be measured with a precision of $0.5-5 \%$ for $\delta^{234} \mathrm{U}$, which is defined as a measure of the fractional deviation of the ${ }^{234} \mathrm{U} /{ }^{238} \mathrm{U}$ atomic ratio from the value at secular equilibrium (SE) in parts per thousand:

$$
\delta^{234} \mathrm{U}=\left(\left[{ }^{234} \mathrm{U} /{ }^{238} \mathrm{U}\right] /\left[{ }^{234} \mathrm{U} /{ }^{238} \mathrm{U}\right]_{\mathrm{SE}}-1\right) \times 1000
$$

where $\left[{ }^{234} \mathrm{U} /{ }^{238} \mathrm{U}\right]$ is the atomic ratio of ${ }^{234} \mathrm{U}$ and ${ }^{238} \mathrm{U}$ nuclides [Chen et al., 1992].

[4] ICP-quadrupole (Q) MS techniques have also been employed for $\delta^{234} U$ measurements, but typically with a significantly low precision of $10-$ 100\% [Shaw and Francois, 1991; Becker et al., 1999; Halicz et al., 2000; Ketterer et al., 2000; Kraemer et al., 2002]. ICP-QMS, however, provides a low-cost approach and a simple instrumental system compared to ICP-SF-MS, MC-ICP-MS and TIMS. The analytical reproducibility of ICPQMS is limited by the Gaussian peaks characteristic of these instruments. The best previously reported precision $(2 \sigma)$ of $10 \%$ for $\delta^{234} U$ abundance in samples with $1 \mu \mathrm{g}$ uranium was reported by Kraemer et al. [2002] using a combination of PERKIN-ELMER ELAN 6000 ICP-QMS with CETAC U6000 AT+ ultrasonic nebulizer. 
[5] We have developed a new method using an AGILENT TECHNOLOGIES Agilent 7500s ICPQMS with a CETAC MCN-6000 introduction system, and have achieved a precision of $1.5-$ $4 \%$ for samples with $10-100 \mathrm{ng}$ of uranium. This new level of precision was attained by carefully measuring baseline conditions and correcting for biases from mass fractionation and ratio drifting using a double spike technique and standard bracketing methods.

\section{Experiment}

\subsection{Standards and Samples}

[6] We measured the uranium isotopic composition and concentration of three different standard materials: (1) the New Brunswick Laboratories Certified Reference Material 112A (NBL-112A, or CRM145 , formerly NBS 960), a uranium metal standard purified from natural uranium ore, dissolved in $1.5 \mathrm{~N} \mathrm{HNO}_{3}$ [Cheng et al., 2000]; (2) Harwell uraninite (HU-1), prepared at the University of Quebec at Montreal from pitchblende powder [Cheng et al., 2000]; and (3) a speleothem carbonate (CAVE-1B) containing approximately $1500 \mathrm{ppb}$ uranium, collected from Crevice Cave, Missouri USA $\left(37^{\circ} 45^{\prime} \mathrm{N}, 89^{\circ} 50^{\prime} \mathrm{W}\right)$ and dissolved in $1 \mathrm{~N}$ $\mathrm{HNO}_{3}$ [Shen et al., 2002]. For NBL-112A, the accepted $\delta^{234} \mathrm{U}$ value is $-36.94 \pm 0.45$, for HU-1 it is $-0.1 \pm 0.6$ determined by TIMS [Cheng et al., 2000; Shen et al., 2002], and for CAVE-1B it is $2445.9 \pm 3.2$ determined by ICP-SF-MS [Shen et al., 2002]. NBL-112A was measured in replicate to evaluate the instrumental sensitivity, within-run precision, and reproducibility. To inspect possible memory effects (blanks) in the system, $\delta^{234} U$ and [U] were measured sequentially in NBL-112A, HU-1 and CAVE-1B, which span a large range in $\delta^{234} \mathrm{U}$ values.

[7] Natural samples with different matrices were also analyzed. Three 500-ml seawater samples, NW9, NW10 and NW21, were collected from Nanwan, southern Taiwan $\left(21^{\circ} 58^{\prime} \mathrm{N}, 120^{\circ} 42^{\prime} \mathrm{E}\right)$. The samples were filtered with an acid-cleaned $0.45-\mu \mathrm{m}$ acetate cellulose filter and stored acidified in an acid-cleaned polyethylene bottle by adding 0.5-1 g $14 \mathrm{~N} \mathrm{HNO}_{3}$ in the field [Moran et al., 2002]. A speleothem sample, BAU01, was collected from Gruta do Bau, Brazil $\left(10^{\circ} 10^{\prime} \mathrm{S}, 40^{\circ} 50^{\prime} \mathrm{W}\right)$ [Wang et al., 2004], and a coral sample, Lg00-1, from Sumatran Islands, Indonesia $\left(0^{\circ} 02^{\prime} \mathrm{N}\right.$, $94^{\circ} 28^{\prime} \mathrm{E}$ ). The carbonate samples were dissolved in $1 \mathrm{~N} \mathrm{HNO}_{3}$.

\subsection{Spiking and Chemistry}

[8] A double spike, ${ }^{236} \mathrm{U}_{-}{ }^{233} \mathrm{U}$ with an atomic ratio of $1.01057 \pm 0.00050$ [Cheng et al., 2000], was used for mass fractionation correction and uranium quantification. It was added to standards and samples to obtain a ${ }^{235} \mathrm{U} /{ }^{233} \mathrm{U}$ atomic ratio of $\sim 10$ in the mixed solutions, which results in adequate precision for both the $\delta^{234} \mathrm{U}$ and [U] determinations [Edwards et al., 1987; Shen et al., 2002]. To evaluate the potential effects on accuracy of large deviations from the target spiking ratio of $\sim 10$, samples were over-spiked and under-spiked with various ${ }^{235} \mathrm{U} /{ }^{233} \mathrm{U}$ ratios ranging from approximately 4 to 104 . Chemical separations followed the procedures described in Shen et al. [2003], including $\mathrm{Fe}$ co-precipitation and anion-exchange chromatography (AG 1-X8 resin, 100-200 mesh).

\subsection{Instrumentation}

[9] An AGILENT TECHNOLOGIES Agilent 7500 s ICP-QMS, housed at the Department of Geosciences, National Taiwan University, was used in this study. Instrumental settings are listed in Table 1. A desolvation nebulization device, a MCN-6000, was used as a dry sample introduction system to provide a fivefold to tenfold enhancement in sensitivity and to reduce interferences from oxides and hydrides. The optimal uranium ion intensity was achieved with a sweep Ar flow of $3.1-4.0 \mathrm{~L} / \mathrm{min}$. No nitrogen was used during the analyses.

[10] The optimal condition of the low resolution mode of our ICP-QMS was determined by analyzing NBL-112A at different peak widths $(10 \%)$ of $0.5-0.9$ atomic mass units (amu) using a standard bracketing method. A consistency of measured $\delta^{234} \mathrm{U}$ values was observed between peak widths of 0.6-0.8 amu (Figure 1). In contrast, the measured $\delta^{234} \mathrm{U}$ values were $5-6 \%$ low between $0.50-0.55 \mathrm{amu}$ and slightly high at $0.9 \mathrm{amu}$. As a consequence, our ICP-QMS was determined to operate optimally using a peak width of 0.70 0.75 (amu) in electrostatic peak hopping mode. Ion beams were detected with a secondary electron multiplier in counting mode. Integration times were $0.1 \mathrm{~s}, 0.1 \mathrm{~s}, 0.4 \mathrm{~s}, 0.05 \mathrm{~s}, 0.1 \mathrm{~s}$, and $0.025 \mathrm{~s}$ for $\mathrm{m} / \mathrm{z}=228,233,234,235,236$ and 237 , respectively. Instrumental background was monitored at $\mathrm{m} / \mathrm{z}=228$, and a typical level was $5-10 \mathrm{cps}$, which is $\sim 5 \%$ of the intensity of ${ }^{234} \mathrm{U}$ ion beam. Abundance sensitivity of ${ }^{238} U$ was 20 $40 \times 10^{-6}$ at $\mathrm{m} / \mathrm{z}=237$ and less than $1 \times 10^{-6}$ at $\mathrm{m} / \mathrm{z}=236$. Spectral interferences from polyatomic 
Table 1. Operating Conditions for ICP-QMS and MCN-6000

\begin{tabular}{ll}
\hline & \multicolumn{1}{c}{ Value/Description } \\
\hline \multicolumn{1}{c}{ Sample Introduction System $M C N-6000$} \\
Sweep Ar & $3.1-4.0 \mathrm{~L} / \mathrm{min}$ \\
$\mathrm{N}_{2}$ & $0 \mathrm{~L} / \mathrm{min}$ \\
Sample uptake rate & $30 \mu \mathrm{L} / \mathrm{min}$ \\
Spray chamber temperature & $75{ }^{\circ} \mathrm{C}$ \\
Desolvator temperature & $160{ }^{\circ} \mathrm{C}$ \\
& \\
\multicolumn{1}{c}{ ICP-QMS: Agilent $7500 \mathrm{~s}$} \\
RF power & $1500 \mathrm{~W}$ \\
Plasma gas flow & $15 \mathrm{~L} / \mathrm{min}$ \\
Auxiliary gas flow & $0.90 \mathrm{~L} / \mathrm{min}$ \\
Sample gas flow & $0.4-0.5 \mathrm{~L} / \mathrm{min}$ \\
Sample (Torch) depth & $8.5-9.0 \mathrm{~mm}$ \\
Torch-H & $0.8-1.5 \mathrm{~mm}$ \\
& \\
Peak width (10\%) & Data Acquisition \\
Scan mode & $0.70-0.75 \mathrm{amu}$ \\
Detection mode & Peak hopping \\
Integration time & Counting mode \\
& $0.1 \mathrm{~s}$ at m/z $=228,0.1 \mathrm{~s}$ \\
& at $233,0.4 \mathrm{~s}$ \\
& at $234,0.05 \mathrm{~s}$ \\
& at $235,0.1 \mathrm{~s}$ \\
& at $236,0.025 \mathrm{~s}$ \\
& at 237 \\
\hline
\end{tabular}

complexes and tailing characteristics of the ${ }^{238} \mathrm{U}$ ion beam was examined at $\mathrm{m} / \mathrm{z}=237$. Oxide $\left(\mathrm{UO}^{+} /\right.$ $\left.\mathrm{U}^{+}\right)$and hydride $\left(\mathrm{UH}^{+} / \mathrm{U}^{+}\right)$levels were less than $2 \times 10^{-3}$ and $2 \times 10^{-6}$, respectively. For a $40-$ $80 \mathrm{ppb}$ uranium solution at a sample uptake rate of $30 \mu \mathrm{L} / \mathrm{min}$, typical ion beam intensities were: $2-3 \times 10^{4} \mathrm{cps}$ at $\mathrm{m} / \mathrm{z}=233$ and $236,2-3 \times$ $10^{3} \mathrm{cps}$ at 234 , and $2-3 \times 10^{5} \mathrm{cps}$ at 235 . An overall sensitivity (ions counted/atoms introduced) was $3-4 \times 10^{-4}$. Total measurement times were 15-20 min. [U] was calculated using a ${ }^{238} \mathrm{U}$ isotope abundance of 0.99280 and natural ${ }^{238} \mathrm{U} /{ }^{235} \mathrm{U}$ atomic ratio of $137.88 \pm 0.1$ [Cowan and Adler, 1977; Steiger and Jager, 1977].

[11] After measuring each sample, the spray chamber and nebulizer were removed from the MCN6000 device and were washed manually using 1\% $\mathrm{HNO}_{3}$. This additional 5-10-min cleaning step significantly reduced the instrumental blank to less than $0.01 \%$ of the original ion beams. Correction for this trivial blank was not included in the off-line data reduction process.

[12] In addition to the instrumental background and memory blank, there are three sources of bias: uncertainty of ion counter dead time, mass fractionation (or mass bias) and Gaussian peak shape. The ion counter dead time was set at $46.9 \mathrm{~ns}$ with an uncertainty less than $2.0 \mathrm{~ns}$, determined by measuring ${ }^{235} \mathrm{U} /{ }^{238} \mathrm{U}$ ratios with different ${ }^{238} \mathrm{U}$ intensities of $0.2-2 \times 10^{6} \mathrm{cps}$. When the intensity difference between ${ }^{235} \mathrm{U}$ ion beams in standards and samples is kept below $2 \times 10^{5} \mathrm{cps}$, the dead time uncertainty results in at most a $0.2 \%$ error in the measured ${ }^{234} \mathrm{U} /{ }^{235} \mathrm{U}$ ratio.

\subsection{Off-Line Data Reduction}

[13] To correct for the mass fractionation, which occurs in mass spectrometers with an ICP source [e.g., Olesik, 2000], the measured atomic ratios were normalized to ${ }^{236} \mathrm{U} /{ }^{233} \mathrm{U}=1.01057$ using an exponential law [Russell et al., 1978]. The characteristics of Gaussian peaks limit the accuracy and precision of isotopic ratio measurements made by mass spectrometers using a quadrupole mass filter. The measured isotopic ratio could vary gradually over time, for instance. We maintained the same analytical condition for 2 hours, for example, and documented a $6 \%$ drifting for NBL-112A $\delta^{234} \mathrm{U}$ values (Figure $2 \mathrm{a}$ ). In addition, an offset of $4 \%$ is observed between two means of replicate analyses of NBL-112A (Figures 2a and 2b). Accordingly, the NBL-112A standard solution was used to bracket every two samples to correct for the ratio drifting. The mass fractionation-corrected atomic ratios were calibrated with a formula:

$$
D_{f}=\frac{\log \left(\frac{234}{238} U\right)_{\text {measured }}}{\log \left(\frac{234 U}{238}\right)}
$$

where $D_{f}$ is drift correction factor, calculated by comparing the measured ${ }^{234} \mathrm{U} /{ }^{238} \mathrm{U}$ atomic ratio of

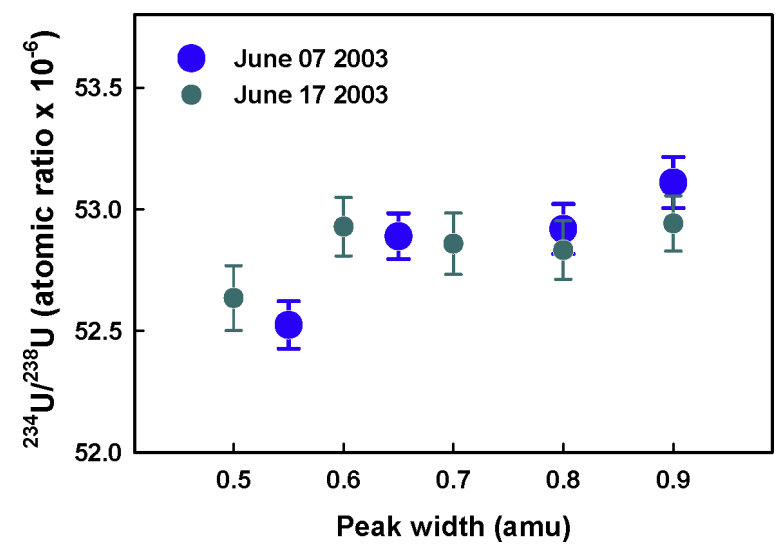

Figure 1. The observed relationship between the ${ }^{234} \mathrm{U} /{ }^{238} \mathrm{U}$ atomic ratio and peak width. The value of the ${ }^{234} \mathrm{U} /{ }^{238} \mathrm{U}$ ratio is $5-6 \%$ lower at $0.50-0.55 \mathrm{amu}$ and slightly higher at $0.9 \mathrm{amu}$ compared to the value at $0.6-0.8 \mathrm{amu}$. 


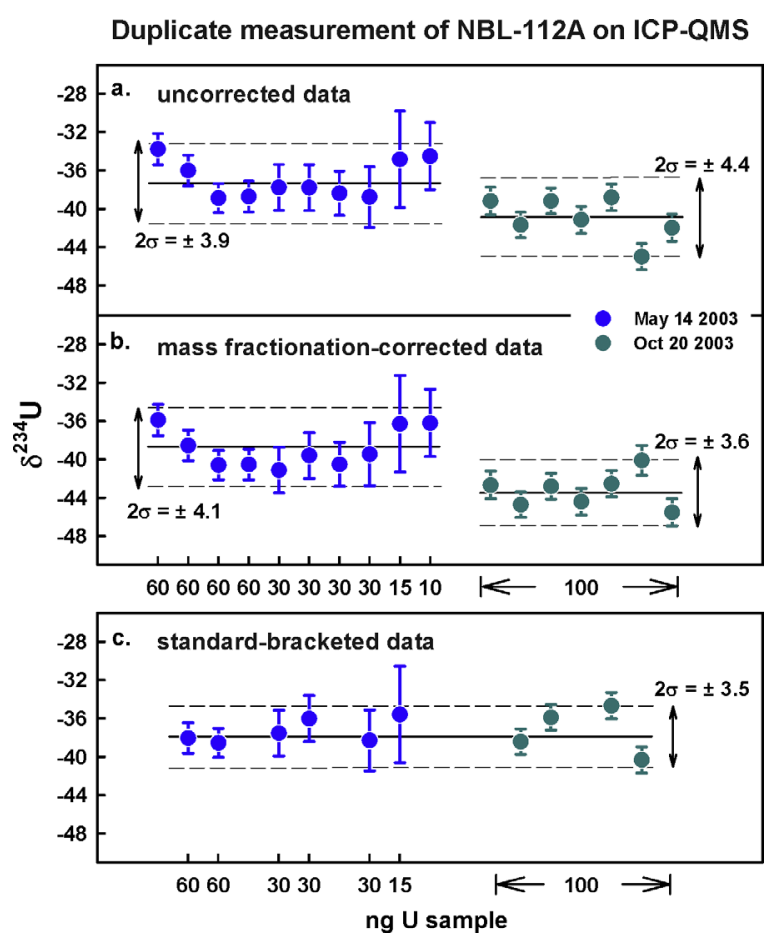

Figure 2. Duplicate ICP-QMS measurements of $\delta^{234} \mathrm{U}$ on NBL-112A on 14 May 2003 (blue circles) and 20 October 2003 (dark cyan circles). (a) An offset of $4 \%$ is observed between the means of the two uncorrected measured data sets. (b) After mass fractionation correction, the external precision of $\delta^{234} U$ data can be improved for the second data set; however, a $6 \%$ drifting is still observed for the first data set. (c) The ratio drifting and discrepancy between the means of the two data sets can be corrected with the standard bracketing method.

NBL-112A with the true value, which is assumed to be $52.859 \times 10^{-6}$ [Cheng et al., 2000]. The values of $D_{f}$ ranged from $0.998-1.000$.

[14] Instrumental background, mass fractionation, and ratio drifting were corrected step by step in an off-line data reduction process, modified from Shen et al. [2002]. The interferences of abundance sensitivity tails and hydride levels were less than $0.1 \%$ and no corrections were employed. Decay constants used were $2.8263 \times 10^{-6}$ year $^{-1}$ for ${ }^{234} \mathrm{U}$ [Cheng et al., 2000], and $1.55125 \times 10^{-10}$ year ${ }^{-1}$ for ${ }^{238} \mathrm{U}$ [Jaffey et al., 1971]. All instrumental analyses are given in Table 2. Errors in this paper are two standard deviations $(2 \sigma)$ unless otherwise noted. For comparison, aliquots of standards and samples were also measured by ICP-SFMS using a Finnigan ELEMENT at the University of Minnesota [Shen et al., 2002] and using a Thermo Electron ELEMENT II at the National
Taiwan University, and/or by TIMS using a Finnigan MAT 262 at the University of Minnesota [Cheng et al., 2000]. A "Student" $t$-test $(\mathrm{p}=0.05)$ was used for comparison of different instrumental data [Miller and Miller, 1988].

\section{Results and Discussion}

\subsection{Standard Measurements}

[15] The results of repeated measurements of NBL112A between May 2003 and October 2003 are shown in Figure 2 and Table 2. Aliquots of NBL112 a ranging from 10 to $100 \mathrm{ng}$ of uranium were measured with an internal precision of $\pm 1.5-4 \%$ o for $\delta^{234} \mathrm{U}$. Using the double spike technique and the standard bracketing method, an external precision of $\pm 3.5 \%$ for $\delta^{234} \mathrm{U}$ was achieved (Figure $2 \mathrm{c}$ ).

[16] The average $\delta^{234} U$ value of 9 duplicates of HU-1, analyzed over the course of one year, is $0.1 \pm 3.3$, and is consistent with the data measured by TIMS $(-0.1 \pm 0.6)$ and by ICP-SF-MS $(0.4 \pm 1.4)$ (Figure 3a) [Cheng et al., 2000; Shen et al., 2002]. For the high- $\delta^{234} U$ CAVE-1B standard, a mean of $2438 \pm 14$, determined by the ICP-QMS technique, shows no difference from ICP-SF-MS data (Figure 3b).

[17] The [U] determinations for the two standards, HU-1 and CAVE-1B, measured by ICP-QMS and by TIMS are not significantly different (Figure 4). For HU-1, there is only an insignificant residual of $-1.5 \pm 2.4 \mathrm{ppb}$, for example, between the [U] data of $959 \pm 2 \mathrm{ppb}$ determined by ICP-QMS from the value, $960.5 \pm 1.3 \mathrm{ppb}$, determined by ICP-SF-MS [Shen et al., 2002] (Figure 4a). For CAVE-1B, ICP-QMS and ICP-SF-MS data are in agreement within analytical error (Figure 4b).

\subsection{Precision and Reproducibility}

[18] The $\delta^{234} U$ measurements for the standards are reproducible to $3.5 \%$ for NBL-112A, 3.3\% for HU-1, and 4\% for CAVE-1B, even though the within-run error of a single measurement can be as low as $1.5 \%$ (Figures 2 and 3). Even when the intensity of the ${ }^{235} \mathrm{U}$ beam ranges from $1 \times 10^{5}-$ $6 \times 10^{5} \mathrm{cps}$ (or for ${ }^{234} \mathrm{U}, 1-6 \times 10^{3} \mathrm{cps}$ ), the ICPQMS method can produce an average between-run reproducibility of $3.5 \%$. The instrumental memory blanks were evaluated with repeated measurements of HU-1 and CAVE-1B, which have largely disparate $\delta^{234} \mathrm{U}$ values. Indistinguishable $\delta^{234} \mathrm{U}$ values of 2424-2452 for CAVE-1B were measured on the ICP-QMS even after analyzing HU-1 with a low 
Table 2. Measurements of ${ }^{234} \mathrm{U} /{ }^{238} \mathrm{U}$ Atomic Ratio, $\delta^{234} \mathrm{U}$, and [U] on Mass Spectrometers

\begin{tabular}{|c|c|c|c|c|c|c|c|c|}
\hline \multirow[b]{2}{*}{ Sample ID } & \multirow[b]{2}{*}{$\mathrm{U}, \mathrm{ng}$} & \multicolumn{2}{|c|}{${ }^{234} \mathrm{U}^{238} \mathrm{U}_{\text {atomic ratio }}$} & \multicolumn{2}{|c|}{$\delta^{234} \mathrm{U}$} & \multicolumn{2}{|c|}{$[\mathrm{U}]$} & \multirow[b]{2}{*}{ Method $^{\mathrm{a}}$} \\
\hline & & $\times 10^{-6}$ & $2 \sigma$ & $\%$ & $2 \sigma$ & $\mathrm{ppb}$ & $2 \sigma$ & \\
\hline \multirow[t]{13}{*}{ NBL-112A } & 60 & 52.80 & \pm 0.09 & -38.0 & \pm 1.6 & & & ICP-QMS \\
\hline & 60 & 52.77 & \pm 0.08 & -38.5 & \pm 1.5 & & & ICP-QMS \\
\hline & 30 & 52.83 & \pm 0.13 & -37.5 & \pm 2.4 & & & ICP-QMS \\
\hline & 30 & 52.91 & \pm 0.13 & -36.0 & \pm 2.4 & & & ICP-QMS \\
\hline & 30 & 52.78 & \pm 0.17 & -38.3 & \pm 3.2 & & & ICP-QMS \\
\hline & 15 & 52.93 & \pm 0.28 & -35.6 & \pm 5.0 & & & ICP-QMS \\
\hline & 100 & 52.78 & \pm 0.07 & -38.4 & \pm 1.3 & & & ICP-QMS \\
\hline & 100 & 52.92 & \pm 0.07 & -35.9 & \pm 1.3 & & & ICP-QMS \\
\hline & 100 & 52.98 & \pm 0.08 & -34.7 & \pm 1.4 & & & ICP-QMS \\
\hline & 100 & 52.67 & \pm 0.07 & -40.3 & \pm 1.4 & & & ICP-QMS \\
\hline & 100 & 52.86 & \pm 0.03 & -37.0 & \pm 0.6 & & & TIMS $^{1}$ \\
\hline & 50 & 52.87 & \pm 0.06 & -36.7 & \pm 1.1 & & & TIMS $^{2}$ \\
\hline & 30 & 52.85 & \pm 0.07 & -37.1 & \pm 1.2 & & & ICP-SF-MS $^{1}$ \\
\hline \multirow[t]{11}{*}{ HU-1 } & 80 & 54.84 & \pm 0.16 & -0.8 & \pm 2.8 & 961.3 & \pm 2.9 & ICP-QMS \\
\hline & 35 & 54.92 & \pm 0.11 & 0.6 & \pm 2.0 & 959.8 & \pm 1.4 & ICP QMS \\
\hline & 30 & 54.96 & \pm 0.12 & 1.4 & \pm 2.2 & 960.2 & \pm 1.3 & ICP QMS \\
\hline & 30 & 54.92 & \pm 0.10 & 0.6 & \pm 1.9 & 960.5 & \pm 1.3 & ICP QMS \\
\hline & 50 & 54.81 & \pm 0.14 & -1.3 & \pm 2.6 & 958.4 & \pm 2.0 & ICP-QMS \\
\hline & 70 & 54.71 & \pm 0.15 & -3.2 & \pm 2.7 & 959.0 & \pm 2.4 & ICP-QMS \\
\hline & 60 & 54.89 & \pm 0.13 & 0.0 & \pm 2.4 & 958.2 & \pm 2.0 & ICP-QMS \\
\hline & 50 & 54.98 & \pm 0.15 & 1.8 & \pm 2.7 & 958.1 & \pm 2.2 & ICP-QMS \\
\hline & 40 & 54.98 & \pm 0.15 & 1.7 & \pm 2.8 & 959.5 & \pm 2.4 & ICP-QMS \\
\hline & 100 & 54.88 & \pm 0.03 & -0.1 & \pm 0.6 & 960.6 & \pm 1.1 & TIMS $^{1}$ \\
\hline & 20 & 54.91 & \pm 0.08 & 0.4 & \pm 1.4 & 960.5 & \pm 1.3 & ICP-SF-MS $^{1}$ \\
\hline \multirow[t]{8}{*}{ CAVE-1B } & 70 & 189.35 & \pm 0.16 & 2449.8 & \pm 3.0 & 1537.8 & \pm 1.3 & ICP-QMS \\
\hline & 30 & 188.41 & \pm 0.27 & 2432.7 & \pm 5.0 & 1541.4 & \pm 2.1 & ICP-QMS \\
\hline & 30 & 188.65 & \pm 0.26 & 2437.1 & \pm 4.8 & 1540.6 & \pm 2.1 & ICP-QMS \\
\hline & 30 & 188.95 & \pm 0.25 & 2442.5 & \pm 4.6 & 1539.4 & \pm 2.0 & ICP-QMS \\
\hline & 40 & 188.38 & \pm 0.35 & 2432.3 & \pm 6.3 & 1541.7 & \pm 3.1 & ICP-QMS \\
\hline & 55 & 188.24 & \pm 0.37 & 2429.6 & \pm 6.7 & 1539.2 & \pm 3.4 & ICP-QMS \\
\hline & 20 & 188.81 & \pm 0.44 & 2440.0 & \pm 8.1 & 1541.0 & \pm 3.9 & ICP-QMS \\
\hline & 15 & 189.13 & \pm 0.18 & 2445.9 & \pm 3.2 & 1541.7 & \pm 2.2 & ICP-SF-MS $^{2}$ \\
\hline \multicolumn{9}{|l|}{ Seawater } \\
\hline \multirow[t]{2}{*}{ NW9 } & 23 & 62.92 & \pm 0.26 & 146.3 & \pm 4.7 & 3.118 & \pm 0.014 & ICP-QMS \\
\hline & 20 & 62.99 & \pm 0.07 & 147.6 & \pm 1.3 & 3.121 & \pm 0.004 & ICP-SF-MS $^{2}$ \\
\hline \multirow[t]{2}{*}{ NW10 } & 19 & 63.11 & \pm 0.26 & 149.8 & \pm 4.8 & 3.111 & \pm 0.015 & ICP-QMS \\
\hline & 20 & 62.93 & \pm 0.08 & 146.5 & \pm 1.5 & 3.112 & \pm 0.004 & ICP-SF-MS $^{2}$ \\
\hline \multirow[t]{3}{*}{ NW21 } & 15 & 62.97 & \pm 0.33 & 147.2 & \pm 6.0 & 3.111 & \pm 0.017 & ICP-QMS \\
\hline & 20 & 62.93 & \pm 0.09 & 146.5 & \pm 1.6 & 3.121 & \pm 0.004 & ICP-SF-MS $^{2}$ \\
\hline & & & & Coral & & & & \\
\hline \multirow[t]{2}{*}{ LG00-1 } & 22 & 62.97 & \pm 0.27 & 147.3 & \pm 4.9 & 2756.4 & \pm 18.7 & ICP-QMS \\
\hline & 20 & 62.97 & \pm 0.09 & 147.2 & \pm 1.7 & 2767.1 & \pm 6.5 & ICP-SF-MS $^{2}$ \\
\hline \multicolumn{9}{|l|}{ Speleothem } \\
\hline \multirow[t]{2}{*}{ BAU01 } & 6 & 77.17 & \pm 0.51 & 406.0 & \pm 9.2 & 127.9 & \pm 0.6 & ICP-QMS \\
\hline & 5 & 77.57 & \pm 0.30 & 413.2 & \pm 5.5 & 127.1 & \pm 0.3 & ICP-SF-MS $^{2}$ \\
\hline
\end{tabular}

$\delta^{234} \mathrm{U}$ (Figure 3b). This illustrates that the low instrumental blanks are insignificant and that no contamination was introduced from the preceding sample after physically cleaning the introduction system between runs [Shen et al., 2002]. The reproducibility of [U] determination is $2 \%$, slightly larger than the within-run precision of $1-2 \%$ (Figure 4).

\subsection{Seawater, Coral, and Speleothem Samples}

[19] The $\delta^{234} U$ data of three 5-8-g aliquots of seawater samples, NW9, NW10 and NW21, measured by ICP-QMS are $146.3 \pm 4.7,149.8 \pm 4.8$, $147.2 \pm 5.9$, respectively, consistent with the ICPSF-MS data with a precision of $1-2 \%$ (Figure $5 \mathrm{a}$ ). This compares favorably with the $\delta^{234} \mathrm{U}$ values of 

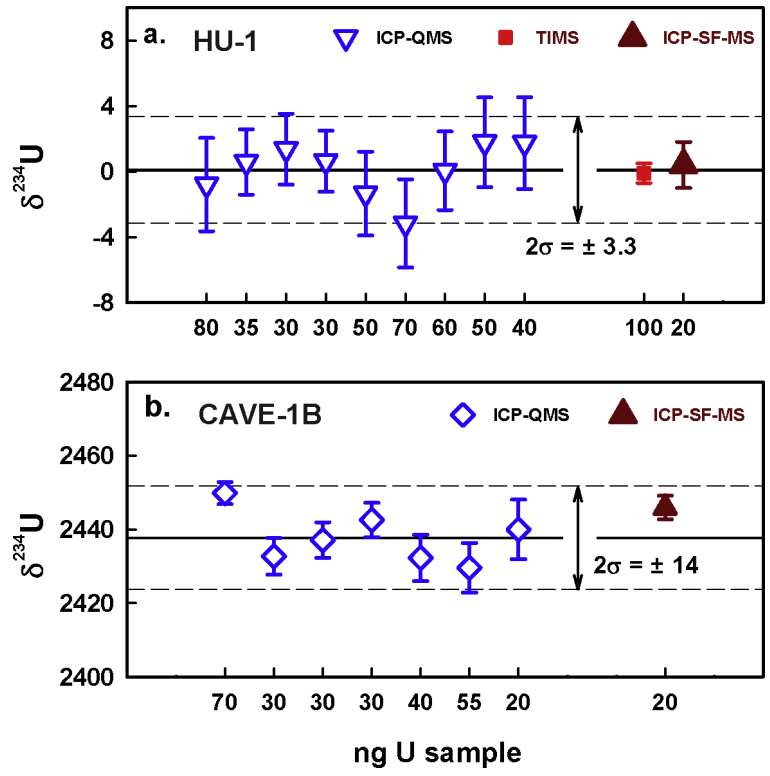

Figure 3. Repeated ICP-QMS measurements of $\delta^{234} U$ on (a) HU-1 (hollow triangles) and (b) CAVE-1B (diamonds) using the standard bracketing method. ICPQMS values show no significant difference from the data measured by ICP-SF-MS (solid triangles) and TIMS (square).

open ocean seawater which is $146 \pm 2$ [Chen et al., 1986]. The $\delta^{234} U$ data of coral Lg00-1 (147.3 \pm 4.9) and speleothem BAU01 (406.0 \pm 9.2) also agree with ICP-SF-MS data. [U] data of five
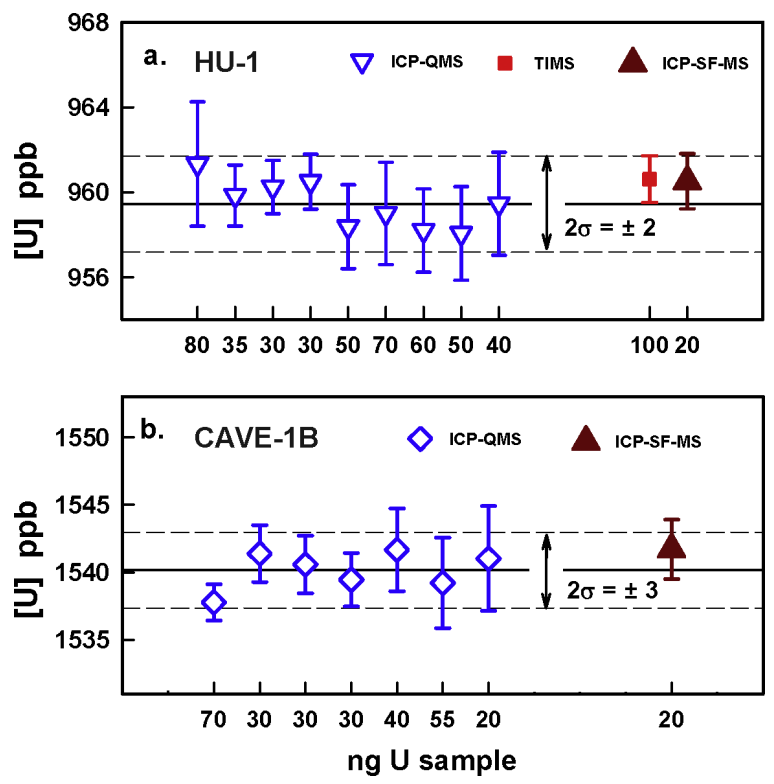

Figure 4. Duplicate ICP-QMS measurements of [U] on (a) HU-1 (hollow triangles) and (b) CAVE-1B (diamonds). ICP-QMS data closely match those measured by ICP-SF-MS (triangles) and TIMS (square).

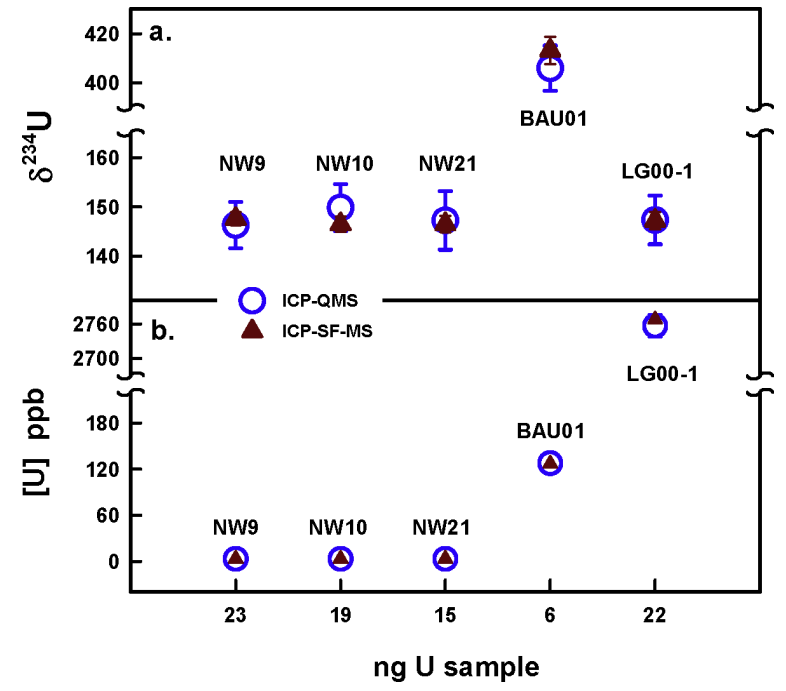

Figure 5. Comparison of ICP-QMS (circles) and ICP-SF-MS (triangles) measurements of $\delta^{234} U$ and [U] on three seawater samples (NW9, NW10, and NW21), one speleothem sample (BAU01), and one coral sample (LG00-1). All data are all consistent within error.

natural samples with analytical errors of $4-7 \%$, all match ICP-SF-MS data even for under-spiked $\left({ }^{235} \mathrm{U} /{ }^{233} \mathrm{U}=104\right.$ for $\left.\operatorname{Lg} 00-1\right)$ and over-spiked $\left({ }^{235} \mathrm{U}^{233} \mathrm{U}=3.9\right.$ for BAU01) samples (Figure $5 \mathrm{~b}$ ). The two ICP-MS data sets are consistent within error and provide further evidence that permil-level precision isotopic measurements can be achieved by ICP-QMS for samples with different matrices. The amount of uranium analyzed ranged from $6-$ $23 \mathrm{ng}$.

[20] [U] was $3.1 \pm 0.1 \mathrm{ppb}$ for the three Nanwan seawater samples with a salinity of 33.8-34.0 (H.J. Lee, personal communication, 2004). A value of $3.2 \pm 0.1 \mathrm{ppb}$ seawater [U], normalized to a salinity of 35 , is consistent to those, $3.2-3.3 \mathrm{ppb}$, in the previous reports [Chen et al., 1986; Robinson et al., 2004]. [U] in the coral, LG00-1, is $2.75 \mathrm{ppm}$, within an overall range of $1.5-4.0 \mathrm{ppm}$ [Shen and Dunbar, 1995; Edwards et al., 2003].

\subsection{Advantages and Disadvantages}

[21] Samples ranging in sizes from 10 to $100 \mathrm{ng}$ of uranium are generally required to attain an analytical precision of $1 \%$ by MC-ICP-MS and ICP-SFMS [Goldstein and Stirling, 2003]. Although the reproducibility of $2-3.5 \%$, demonstrated here by our new ICP-QMS technique, is slightly higher than those by other ICP-MS's using magneticsector mass analyzers, our method offers the dis- 
tinct advantages of low cost, easy maintenance, and simple instrument operation. As compared with previous ICP-QMS techniques [Shaw and Francois, 1991; Ketterer et al., 2000; Kraemer et al., 2002], the analytical improvement includes signal enhancement and effective corrections for mass fractionation and ratio drifting. Our new technique far exceeds the previous best precision of $10 \%$ using $1 \mu \mathrm{g}$ of uranium for $\delta^{234} \mathrm{U}$ measurements, published by Kraemer et al. [2002]. Using only $30 \mathrm{ng}$ of uranium (or $1.5 \mathrm{pg}$ of ${ }^{234} \mathrm{U}$ ), $\delta^{234} \mathrm{U}$ and $[\mathrm{U}]$ data with errors better than $4 \%$ can be achieved using this newly developed method. This corresponds to $10 \mathrm{~g}$ of seawater [Robinson et al., 2004], 10-14 mg of coral [Edwards et al., 1987; Shen et al., 2005], $<15 \mathrm{mg}$ of marine sediment [Moran et al., 2005], or 10-300 mg of speleothem material [Dorale et al., 2004; Wang et al., 2004].

[22] This technique, however, is still constrained by the relative lower sensitivity and higher instrumental background compared to the ICP-SF-MS technique [Shen et al., 2002]. An overall sensitivity of $3-4 \times 10^{-4}$ is significantly lower than the $1-$ $10 \times 10^{-3}$ sensitivities of MC-ICP-MS and ICPSF-MS techniques [Stirling et al., 2000; Turner et al., 2001; Pietruszka et al., 2002; Shen et al., 2002; Deschamps et al., 2003; Robinson et al., 2004; Andersen et al., 2004; Fietzke et al., 2005]. The instrumental background of $5-10 \mathrm{cps}$ at $\mathrm{m} / \mathrm{z}=$ $220-240$ of the Agilent 7500 s requires a ${ }^{234} \mathrm{U}$ ion beam intensity of $1,000 \mathrm{cps}$ or higher for $3-4 \%$ precision.

[23] Examples of applications include (1) the oceanic budgets and fluxes of U-series nuclides, (2) evolution of global oceanic circulations, (3) geochronology, and (4) paleoclimatology. In combination with measurements of the thorium isotopic composition, Holocene carbonate samples with ppm levels of uranium could be dateable with a precision better than $\sim 100$ years. A possible instrumental procedure is as follows. After chemical separation, the collected Th and $\mathrm{U}$ fractions would be analyzed consecutively, bracketed with a standard of known $\delta^{234} \mathrm{U}$ value. Counts at $\mathrm{m} / \mathrm{z}=228,229,230$ and 232 would be measured for the Th fraction. With a $0.5-\mathrm{g}$ subsample of Holocene coral, for example, an ${ }^{230} \mathrm{Th}$ ion beam of $>1,000 \mathrm{cps}$ can be measured in 10 min with an expected precision of 5-10\%. For corals younger than 50-100 years, the intensity of ${ }^{230} \mathrm{Th}$ ion beam will be $100 \mathrm{cps}$ or less and the analytical precision will be limited by the background counts of 5-10 cps.

\section{Conclusions}

[24] A simple and precise analytical method of determining the uranium isotopic composition and concentration of natural materials using ICPQMS has been developed. Measurement time is 15-20 min per sample. A precision better than 3\%o for $\delta^{234} \mathrm{U}$ and better than $2 \%$ for [U] can be achieved for samples with 30-ng uranium. Although the ultimate precision and sensitivity offered by this ICP-QMS is slightly less than that of other ICP-MS techniques, such as ICP-SF-MS and MC-ICP-MS, permil-level precision allows its ready application in various fields of the earth sciences.

\section{Acknowledgments}

[25] We thank S.-L. Chung of the National Taiwan University for kindly sharing the Agilent 7500s machine time and H.-Y. Chiu and K.-S. Li for laboratory assistance. R. L. Edwards and $\mathrm{H}$. Cheng of the University of Minnesota generously provided uranium standards and spike solution. Constructive reviews by $\mathrm{K}$. Rubin and one anonymous reviewer significantly improved this paper. We thank K. Rubin for offering TIMS U isotopic data. The manuscript was enhanced through the comments of V. Salters. Funding for this study was provided by Taiwan ROC NSC grants (93-2116-M002-036, 94-2116-M002-012, 94-2752-M002-011-PAE, and 95-2752-M002-012-PAE to C.C.S.).

\section{References}

Andersen, M. B., C. H. Stirling, E.-K. Potter, and A. N. Halliday (2004), Toward epsilon levels of measurement precision on ${ }^{234} \mathrm{U} /{ }^{238} \mathrm{U}$ by using MC-ICPMS, Int. J. Mass Spectrom., 237, 107-118.

Barnes, J. W., E. J. Lang, and H. A. Potratz (1956), Ratio of ionium to uranium in coral limestone, Science, 124, 175176.

Becker, J. S., and H.-J. Dietze (2000), Precise and accurate isotope ratio measurement by ICP-MS, Fresenius J. Anal. Chem., 368, 23-30.

Becker, J. S., H.-J. Dietze, J. A. McLean, and A. Montaser (1999), Ultratrace and isotope analysis of long-lived radionuclides by inductively coupled plasma quadrupole mass spectrometry using a direct injection high efficiency nebulizer, Anal. Chem., 71, 3077-3084.

Bourdon, B., A. Zindler, and G. Worner (1994), Evolution of the Laacher Sea magma chamber: Evidence from SIMS and TIMS measurements of U-Th disequilibria in minerals and glasses, Earth Planet. Sci. Lett., 126, 75-90.

Bourdon, B., A. Zindler, T. Elliott, and C. H. Langmuir (1996), Constraints on mantle melting at mid-ocean ridge from global U-238-Th-230 disequilibrium data, Nature, 384, $231-235$. 
Bourdon, B., S. P. Turner, G. M. Henderson, and C. C. Lundstrom (2003), Introduction to U-series geochemistry, in Uranium-Series Geochemistry, edited by B. Bourdon et al., Rev. Mineral. Geochem., 52, 1-21.

Chen, J. H., and G. J. Wasserburg (1981), Isotopic determination of uranium in picomole and subpicomole quantities, Anal. Chem., 53, 2060-2067.

Chen, J. H., R. L. Edwards, and G. J. Wasserburg (1986), ${ }^{238}$ U, ${ }^{234} \mathrm{U}$ and ${ }^{232} \mathrm{Th}$ in sea water, Earth Planet. Sci. Lett., 80, $241-251$.

Chen, J. H., R. L. Edwards, and G. J. Wasserburg (1992), Mass spectrometry and applications to uranium-series disequilibrium, in Uranium-Series Disequilibrium: Applications to Earth, Marine, and Environmental Sciences, 2nd ed., edited by M. Ivanovich and R. S. Harmon, pp. 174-206, Clarendon, Oxford.

Cheng, H., R. L. Edwards, J. Hoff, C. D. Gallup, D. A. Richards, and Y. Asmerom (2000), The half-lives of uranium234 and thorium-230, Chem. Geol., 169, 17-33.

Cowan, G. A., and H. H. Adler (1977), Variability of natural abundance of U-235, Geochim. Cosmochim. Acta, 40, $1487-1490$.

Deschamps, P., R. Doucelance, B. Ghaleb, and J.-L. Michelot (2003), Further investigations on optimized tail correction and high-precision measurement of uranium isotopic ratios using multi-collector ICP-MS, Chem. Geol., 201, $141-160$.

Dorale, J. A., R. L. Edwards, C. A. Alexander Jr., C.-C. Shen, D. A. Richards, and H. Cheng (2004), Uranium-series dating of speleothems: Current techniques, limits and applications, in Studies of Cave Sediments: Physical and Chemical Records of Paleoclimate, edited by I. D. Sasowsky and J. E. Mylroie, pp. 177-197, Springer, New York.

Edwards, R. L., J. H. Chen, T.-L. Ku, and G. J. Wasserburg (1987), Precise timing of the last interglacial period from mass spectrometric analysis of Th-230 in corals, Science, $236,175-192$

Edwards, R. L., C. D. Gallup, and H. Cheng (2003), Uraniumseries dating of marine and lacustrine carbonates, in Uranium-Series Geochemistry, edited by B. Bourdon et al., Rev. Mineral. Geochem., 52, 363-405.

Fietzke, J., V. Liebetrau, A. Eisenhauer, and Ch. Dullo (2005), Determination of uranium isotope ratios by multi-static MIC-ICP-MS: Method and implementation for precise Uand Th-series isotope measurements, J. Anal. At. Spectrom., 20, 395-401.

Goldstein, S. J., and C. H. Stirling (2003), Techniques for measuring uranium-series nuclides: 1992-2002, in Uranium-Series Geochemistry, edited by B. Bourdon et al., Rev. Mineral. Geochem., 52, 23-57.

Halicz, L., I. Segal, I. Gavrieli, A. Lorber, and Z. Karpas (2000), Determination of the ${ }^{234} U{ }^{238} U$ ratio in water samples by inductively coupled plasma mass spectrometry, Anal. Chim. Acta, 422, 203-208.

Halliday, A. N., D.-C. Lee, J. N. Christensen, A. J. Walder, P. A. Freedman, C. E. Jones, C. M. Hall, W. Yi, and D. Teagle (1995), Recent developments in inductively coupled plasma magnetic sector multiple collector mass spectrometry, Int. J. Mass Spectrom. Ion Processes, 146/ $147,21-33$.

Halliday, A. N., D.-C. Lee, J. N. Christensen, M. Rehkamper, W. Yi, X.-Z. Luo, C. M. Hall, C. J. Ballentine, T. Pettke, and C. Stirling (1998), Applications of multiple collector-ICPMS to cosmochemistry, geochemistry, and paleoceanography, Geochim. Cosmochim. Acta, 62, 919-940.
Hinrichs, J., and B. Schnetger (1999), A fast method for the simultaneous determination of ${ }^{230} \mathrm{Th},{ }^{234} \mathrm{U}$ and ${ }^{235} \mathrm{U}$ with isotope dilution sector field ICP-MS, Analyst, 124, 927932.

Ivanovich, M., and R. S. Harmon (Eds.) (1992), UraniumSeries Disequilibrium: Applications to Earth, Marine, and Environmental Sciences, 2nd ed., 910 pp., Clarendon, Oxford.

Jaffey, A. H., K. F. Flynn, L. E. Glendenin, W. C. Bentley, and A. M. Essling (1971), Precision measurement of half-lives and specific activities of ${ }^{235} \mathrm{U}$ and ${ }^{238} \mathrm{U}$, Phys. Rev., C4, 1889-1906.

Ketterer, M. E., J. A. Jordan, S. C. Szechenyi, D. D. Hudson, and R. Layman (2000), Envirogeochemical exploration for "NORM" wastes: Quadrupole inductively coupled plasma mass spectrometric measurements of thorium and uranium isotopes, J. Anal. At. Spectrom., 15, 1569-1573.

Kraemer, T. F., M. W. Doughten, and T. D. Bullen (2002), Use of ICP/MS with ultrasonic nebulizer for routine determination of uranium activity ratios in natural water, Environ. Sci. Technol., 36, 4899-4904.

Luo, X., M. Rehkämper, D.-C. Lee, and A. N. Halliday (1997), High precision ${ }^{230} \mathrm{Th} /{ }^{232} \mathrm{Th}$ and ${ }^{234} \mathrm{U} /{ }^{238} \mathrm{U}$ measurements using energy-filtered ICP magnetic sector multiple collector mass spectrometry, Int. J. Mass Spectrom. Ion Processes, $171,105-117$

Miller, J. C., and J. N. Miller (1988), Statistics for Analytical Chemistry, 2nd ed., 227 pp., Ellis Horwood, New York.

Moran, S. B., C.-C. Shen, H. N. Edmonds, S. E. Weinstein, J. N. Smith, and R. L. Edwards (2002), Dissolved and particulate ${ }^{231} \mathrm{~Pa}$ and ${ }^{230} \mathrm{Th}$ in the western Atlantic Ocean: Implications for deep water age, boundary scavenging and ${ }^{231} \mathrm{~Pa} /{ }^{230} \mathrm{Th}$ fractionation, Earth Planet. Sci. Lett., 203, 999-1014.

Moran, S. B., C.-C. Shen, R. L. Edwards, H. N. Edmonds, J. C. Scholten, J. N. Smith, and T.-L. Ku (2005), ${ }^{231} \mathrm{~Pa}$ and ${ }^{230} \mathrm{Th}$ in surface sediments of the Arctic Ocean: Implications for ${ }^{231} \mathrm{~Pa} /{ }^{230} \mathrm{Th}$ fractionation, boundary scavenging, and advective export, Earth Planet. Sci. Lett., 234, $235-248$

Olesik, J. W. (2000), Inductively coupled plasma mass spectrometry, in Inorganic Mass Spectrometry: Fundamentals and Applications, edited by C. M. Barshick et al., pp. 67-158, CRC Press, Boca Raton, Fla.

Pietruszka, A. J., R. W. Carlson, and E. H. Hauri (2002), Precise and accurate measurement of ${ }^{226} \mathrm{Ra}^{230}{ }^{2 h}-{ }^{238} \mathrm{U}$ disequilibria in volcanic rocks using plasma ionization multicollector mass spectrometry, Chem. Geol., 188, 171191.

Reid, M. R., C. D. Coath, T. M. Harrison, and K. D. McKeegan (1997), Prolonged residence time for the youngest rhyolites associated with Long Valley Caldera, ${ }^{230} \mathrm{Th}-{ }^{238} \mathrm{U}$ ion microprobe dating of young zircons, Earth Planet. Sci. Lett., 150, 27-39.

Robinson, L. F., N. S. Belshaw, and G. M. Henderson (2004), $\mathrm{U}$ and $\mathrm{Th}$ concentrations and isotope ratios in modern carbonates and waters from the Bahamas, Geochim. Cosmochim. Acta, 68, 1777-1789.

Rubin, K. H., I. van der Zander, M. C. Smith, and E. C. Bergmanis (2005), Minimum speed limit for ocean ridge magmatism from ${ }^{210} \mathrm{~Pb}_{-}{ }^{226} \mathrm{Ra}^{230} \mathrm{Th}$ disequilibria, Nature, 437, 534-538.

Russell, W. A., D. A. Papanastassiou, and T. A. Tombrello (1978), Ca isotope fractionation on the Earth and other solar system materials, Geochim. Cosmochim. Acta, 42, 10751090. 
Shaw, T. J., and R. Francois (1991), A fast and sensitive ICP-MS assay for the determination of ${ }^{230} \mathrm{Th}$ in marine sediments, Geochim. Cosmochim. Acta, 55, 2075-2078.

Shen, C.-C., R. L. Edwards, H. Cheng, J. A. Dorale, R. B. Thomas, S. B. Moran, S. E. Weinstein, and M. Hirschmann (2002), Uranium and thorium isotopic and concentration measurements by magnetic sector inductively coupled plasma mass spectrometry, Chem. Geol., 185, 165-178.

Shen, C.-C., H. Cheng, R. L. Edwards, S. B. Moran, H. N. Edmonds, J. A. Hoff, and R. B. Thomas (2003), Measurement of attogram quantities of ${ }^{231} \mathrm{~Pa}$ in dissolved and particulate fractions of seawater by isotope dilution thermal ionization mass spectroscopy, Anal. Chem., 75, 10751079.

Shen, C.-C., T. Lee, K.-K. Liu, H.-H. Hsu, R. L. Edwards, C.-H. Wang, M.-Y. Lee, Y.-G. Chen, H.-J. Lee, and H.-T. Sun (2005), An evaluation of quantitative reconstruction of past precipitation records using coral skeletal $\mathrm{Sr} / \mathrm{Ca}$ and $\delta^{18} \mathrm{O}$ data, Earth Planet. Sci. Lett., 237, 370-386.

Shen, G. T., and R. B. Dunbar (1995), Environmental controls on uranium in reef corals, Geochim. Cosmochim. Acta, 59, 2009-2024.
Steiger, R. H., and E. Jager (1977), Subcommision on geochronology - Convention on use of decay constants in geochronology and cosmochronology, Earth Planet. Sci. Lett., 36, 359-362.

Stirling, C. H., T. M. Esat, and M. T. McCulloch (1995), Highprecision U-series dating of corals from Western Australia and implications for the timing and duration of the Last Interglacial, Earth Planet. Sci. Lett., 135, 115-130.

Stirling, C. H., D.-C. Lee, J. N. Christensen, and A. N. Halliday (2000), High-precision in situ ${ }^{238} \mathrm{U}^{234} \mathrm{U}^{230} \mathrm{Th}$ isotopic analysis using laser ablation multiple-collector ICPMS, Geochim. Cosmochim. Acta, 64, 3737-3750.

Turner, S., P. van Calsteren, N. Vigier, and L. Thomas (2001), Determination of thorium and uranium isotope ratios in low concentration geological materials using a fixed multi-collector-ICP-MS, J. Anal. At. Spectrom., 16, $612-615$.

Wang, X., A. S. Auler, R. L. Edwards, H. Cheng, P. S. Cristalli, P. L. Smart, D. A. Richards, and C.-C. Shen (2004), Northeastern Brazil wet periods linked to distant climate anomalies and rainforest boundary changes, Nature, $432,740-743$. 